\title{
High production of bioactive depsides in shoot and callus cultures of Aronia arbutifolia and Aronia $\times$ prunifolia
}

\author{
Agnieszka Szopa $^{1}$ (D) $\cdot$ Paweł Kubica ${ }^{1} \cdot$ Anna Snoch $^{1} \cdot$ Halina Ekiert $^{1}$
}

Received: 14 May 2017 / Revised: 25 January 2018 / Accepted: 5 February 2018 / Published online: 10 February 2018

(C) The Author(s) 2018. This article is an open access publication

\begin{abstract}
Methanolic extracts from calluses and shoots of Aronia arbutifolia and Aronia $\times$ prunifolia cultivated in vitro were quantitatively analysed for phenolic acids by DAD-HPLC. The cultures were grown on ten variants of Murashige-Skoog medium variants enriched with various concentrations of growth regulators (GRs), BA and NAA, in the concentration range 0.1-3.0 mg/L. The analysed extracts were confirmed to contain from four to six compounds (depsides-chlorogenic acid, neochlorogenic acid, and rosmarinic acid, and also protocatechuic acid, $p$-hydroxybenzoic acid, and 3,4-dihydroxyphenylacetic acid). The total amounts of the metabolites varied considerably, depending on the amounts of the GRs in the tested medium variants, and increased in the callus and shoot extracts, respectively, up to 1.7 and 3.2 times (A. arbutifolia), and 2.2 and 2.7 times (A. $\times$ prunifolia). Maximum total amounts were confirmed in shoot extracts of both plants (approx. 200 and $600 \mathrm{mg} / 100 \mathrm{~g}$ DW, respectively). The main compounds in A. arbutifolia cultures were the depsides—chlorogenic acid, rosmarinic acid, and neochlorogenic acid (max. 91.94, 77.03, $32.57 \mathrm{mg} / 100 \mathrm{~g}$ DW, respectively). The same depsides dominated quantitatively in the cultures of $A$. $\times$ prunifolia (max. 131.82, 206.62 and $257.39 \mathrm{mg} / 100 \mathrm{~g} \mathrm{DW}$, respectively).
\end{abstract}

Keywords Free phenolic acids · Growth regulators · Purple chokeberry · Red chokeberry · Shoot cultures · Callus cultures · HPLC analysis

$\begin{array}{ll}\text { Abbreviations } \\ \text { BA } & \text { 6-Benzyladenine } \\ \text { DAD-HPLC } & \begin{array}{l}\text { High-performance liquid chromatography } \\ \text { with diode array detector }\end{array} \\ \text { DE } & \text { Depsides } \\ \text { DW } & \text { Dry weight } \\ \text { MS } & \text { Murashige-Skoog } \\ \text { NAA } & \alpha \text {-Naphthaleneacetic acid } \\ \text { PA } & \text { Phenolic acids } \\ \text { GRs } & \text { Plant growth regulators }\end{array}$

Communicated by M. Capuana.

Agnieszka Szopa

a.szopa@uj.edu.pl

Halina Ekiert

mfekiert@cyf-kr.edu.pl

1 Chair and Department of Pharmaceutical Botany, Jagiellonian University, Collegium Medicum, ul. Medyczna 9, 30-688 Kraków, Poland

\section{Introduction}

Among phenolic acids (PA) and depsides (DE), e.g., chlorogenic, rosmarinic, and also neochlorogenic acids, are a special object of interest, both from a pharmaceutical and cosmetics point of view (Petersen and Simmonds 2003; Ekiert et al. 2013; Döring and Petersen 2014). The first two DE mentioned have very valuable biological properties, of which the most important are: antioxidant, antiaggregatory, anti-inflammatory, immunostimulating, and anticancer activities (Nakatani et al. 2000; Sato et al. 2011; Meng et al. 2013). Neochlorogenic acid (an isomer of chlorogenic acid) also shows similar properties (Dewick 1997; Thurow 2012).

Among Aronia species, the most famous in Europe is $A$. melanocarpa (black chokeberry), the species with North American natural habitats, successfully planted in many European countries and in Asia (Valcheva-Kuzmanova and Belcheva 2006; Kulling and Rawel 2008; Kokotkiewicz et al. 2010). A less well-known species is A. arbutifolia (red chokeberry), and a hybrid of these two speciesA. $\times$ prunifolia (purple chokeberry). These plants grow as bushes, which are native distributed also in North America, but they are also successfully planted in Asia and Europe. 
The knowledge on the chemical composition of A. arbutifolia and A. $\times$ prunifolia is very poor. Phytochemical studies of fruit extracts performed until now have documented the presence of some groups of polyphenols-proanthocyanidins, anthocyanins, flavonoids, and hydroxycinnamic acids (Celka and Szkudlarz 2010; Taheri et al. 2013). Phytochemical analyses of different parts of soil-grown plants performed by our team (fruits and leaves), from which the investigated in vitro cultures were established, have documented the presence of some anthocyanins (glycosides of cyanidin), flavonoids (quercetin and its glycosides), and some free PA (Szopa et al. 2017a).

Our previous investigations on A. melanocarpa shoot and callus cultures had demonstrated a high biosynthetic capacity of the cells directed towards the production of free PA, in particular hydroxybenzoic acids and cinnamic acid derivatives (Szopa et al. 2013; Szopa and Ekiert 2014). It seemed interesting to explore the biosynthetic potential of the shoot and callus cultures of $A$. arbutifolia and $A . \times$ prunifolia successfully established in our department.

In our previous studies related to A. melanocarpa, we tested variants of Linsmaier-Skoog medium (Linsmaier and Skoog 1965) and Murashige-Skoog (MS) medium (Murashige and Skoog 1962), containing different amounts of BA (6-benzyladenine)—cytokinin, and NAA $(\alpha$-naphthaleneacetic acid) - auxin. We had proven that MSbased media were more conducive to the accumulation of free PA (Szopa et al. 2013; Szopa and Ekiert 2014).

The goal of research was, to investigate the production of free PA in the biomass from in vitro cultures (shoot and callus) of $A$. arbutifolia and A. $\times$ prunifolia cultivated on ten MS medium variants, enriched with BA and NAA at various concentrations in the range $0.1-3.0 \mathrm{mg} / \mathrm{L}$. Free PA, derivatives of benzoic acid and cinnamic acid, including three DE: chlorogenic, neochlorogenic, and rosmarinic acids, were determined in methanolic extracts from the biomass of shoot and callus cultures. In addition, the quantities of cinnamic acid (precursor of one of the subgroups of PA) were estimated.

\section{Materials and methods}

\section{Soil-grown plants}

The material used in the experiment originated from Aronia shrubs, Aronia arbutifolia (L.) Pers. and Aronia $\times$ prunifolia (Marsh.) Rhed., growing in Arboretum in Rogów (Warsaw University of Life Sciences, Forest Experimental Station in Rogów, Poland). The A. arbutifolia and A. $\times$ prunifolia originated from Botanischer Garten Greifswald, Germany, and Wayne County, USA, $166 \mathrm{~m}$ a.s. $1.42^{\circ} 9^{\prime} \mathrm{N}, 83^{\circ} 16^{\prime} \mathrm{W}$; germinated in 1987, 2002, accessions numbers: 12207 and 15768, respectively. The plants' identification was confirmed by the scientific workers of Arboretum. Leaf buds of soil-grown plants were used for the initiation of in vitro cultures (2013). To perform the biotechnological evaluation of results, fruits of both studied Aronia plants (harvested in 2013) were used for comparison.

\section{Initiation of in vitro cultures}

The plant material (leaf buds) was obtained from the plants described above. It was sterilized in $0.1 \% \mathrm{HgCl}_{2}$ for about 10 min and then cultured on MS agar medium (Murashige and Skoog 1962) enriched with: $1 \mathrm{mg} / \mathrm{L}$ BA (6-benzyladenine) and $1 \mathrm{mg} / \mathrm{L}$ NAA ( $\alpha$-naphthaleneacetic acid). After 8 weeks, undifferentiated callus and well-differentiated shoot cultures of $A$. arbutifolia and $A$. $\times$ prunifolia were successfully established (Fig. 1). The cultures were grown under continuous artificial white light $\left(2.75 \mathrm{~W} / \mathrm{m}^{2}, \mathrm{LF}-40 \mathrm{~W}\right.$ lamp, daylight, Piła, Poland) at $25 \pm 2{ }^{\circ} \mathrm{C}$.

\section{In vitro culture experiments}

The experiments with shoot and callus in vitro cultures of A. arbutifolia and A. $\times$ prunifolia (Fig. 1) were maintained on ten MS agar medium variants with different amounts of GRs, BA, and NAA (mg/L): 0.1 and $0.1 ; 0.1$ and $2.0 ; 0.5$ and $2.0 ; 1.0$ and $0.5 ; 1.0$ and $1.0 ; 1.0$ and $1.5 ; 2.0$ and $0.5 ; 2.0$ and 1.0; 2.0 and 2.0; and 3.0 and 1.0. The amount of inoculum was $1 \mathrm{~g}$ for shoot cultures and $2 \mathrm{~g}$ for callus cultures. One growth period lasted 4 weeks. The cultures were grown under continuous white light $\left(2.75 \mathrm{~W} / \mathrm{m}^{2}\right.$, LF-40W lamp, daylight, Piła, Poland) at $25 \pm 2{ }^{\circ} \mathrm{C}$. The collected biomass was dried by lyophilisation. Three series of investigations were repeated three times.

\section{Quantitative estimation of free PA}

The lyophilized and pulverized plant material [each sample $0.5 \mathrm{~g}$ dry weight (DW)] from all tested MS medium variants of $A$. arbutifolia and $A . \times$ prunifolia in vitro cultures (calluses and shoots) was extracted in boiling methanol $(50 \mathrm{~mL})$ for $3 \mathrm{~h}$. The identity and the amounts of the analysed free PA in the methanolic extracts were accomplished by DADHPLC (acc. to Ellnain-Wojtaszek and Zgórka 1999). The details of the DAD-HPLC analysis, equipment, and conditions were the same as those described by (Szopa et al. 2017a) For quantitative analyses, the following PA standards from Sigma-Aldrich Co. were used: caffeic acid, chlorogenic acid, $o-, m-, p$-coumaric acids, 3,4-dihydroxyphenylacetic acid, ferulic acid, gallic acid, gentisic acid, hydrocaffeic acid, $p$-hydroxybenzoic acid, isoferulic acid, neochlorogenic acid, protocatechuic acid, rosmarinic acid, salicylic 


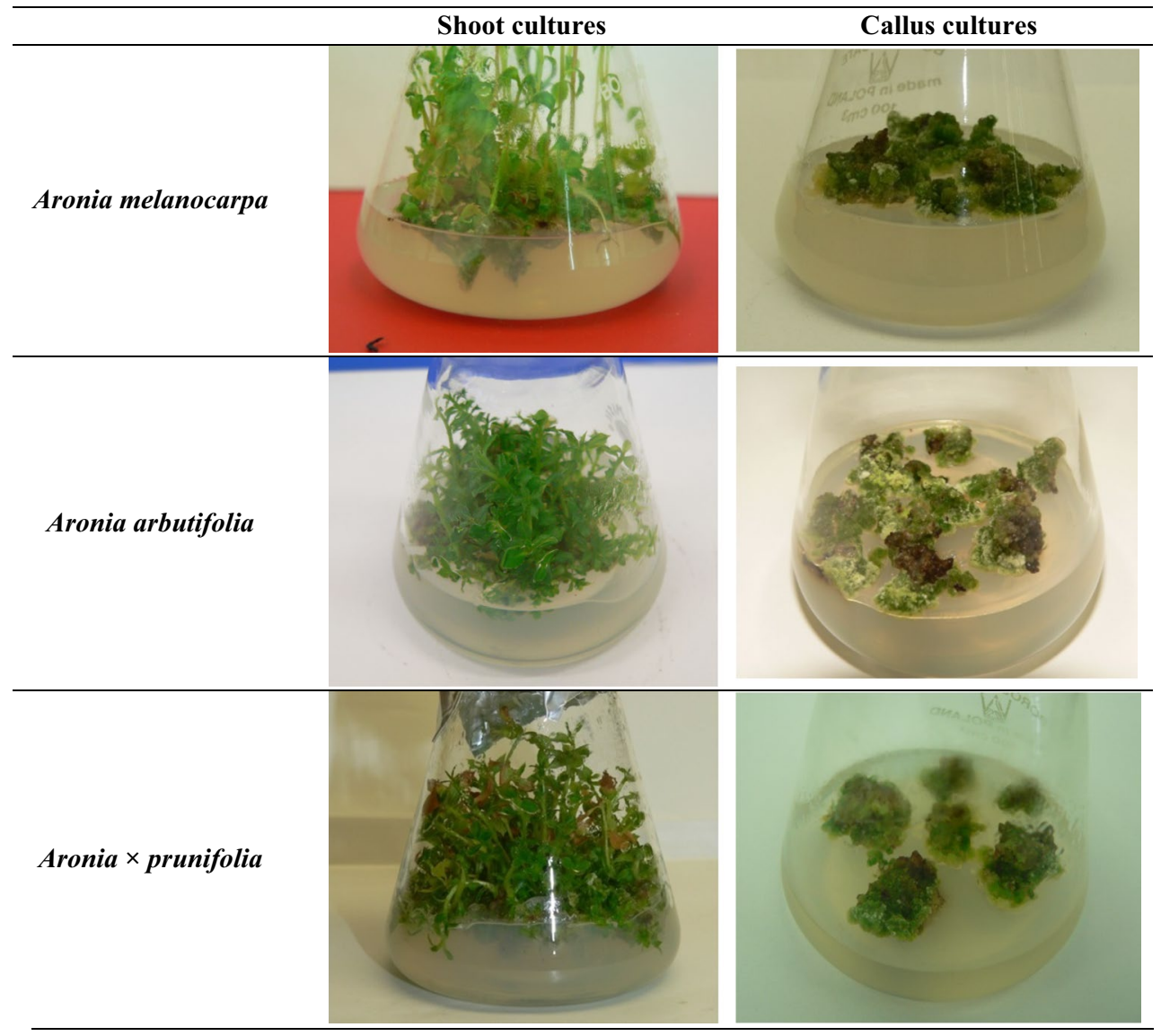

Fig. 1 Shoot and callus in vitro cultures of Aronia melanocarpa (acc. Szopa et al. 2013), and Aronia arbutifolia and Aronia $\times$ prunifolia studied in the current research (agar MS medium with $1 \mathrm{mg} / \mathrm{L}$ BA and $1 \mathrm{mg} / \mathrm{L}$ NAA, 4-week growth cycles)

acid, sinapic acid, syringic acid, and vanillic acid. In addition, cinnamic acid standard (Sigma-Aldrich Co.) was used.

\section{Statistics}

The quantitative results are expressed in $\mathrm{mg} / 100 \mathrm{~g}$ DW (dry weight) as the mean \pm SD of three series of investigations which were repeated three times.

\section{Results}

\section{Shoot cultures of Aronia arbutifolia}

The shoot cultures of A. arbutifolia (Fig. 1) growing on the investigated MS media, containing different concentrations of GRs, were characterized by varying morphology. The shoots were more or less branched and formed more and less numerous green leafy shoots. On some media variants, the surface of leaves was very large $(1 \mathrm{mg} / \mathrm{L} \mathrm{BA}$ and $2 \mathrm{mg} / \mathrm{L} \mathrm{NAA} ; 0.1 \mathrm{mg} / \mathrm{L} \mathrm{BA}$ and $0.1 \mathrm{mg} / \mathrm{L} \mathrm{NAA})$. On three MS variants $(0.1 \mathrm{mg} / \mathrm{L}$ BA and $2 \mathrm{mg} / \mathrm{L}$ NAA; $0.5 \mathrm{mg} / \mathrm{L} \mathrm{BA}$ and $2 \mathrm{mg} / \mathrm{L}$ NAA; and $1 \mathrm{mg} / \mathrm{L} \mathrm{BA}$ and $0.5 \mathrm{mg} / \mathrm{L} \mathrm{NAA}$ ), the shoots formed callus tissue at the base.

In shoot cultures of $A$. arbutifolia growing on ten investigated MS media, from 4.54- to 7.07-fold increases in dry biomass were found during growth periods (4 weeks). More than 6.7-fold increases were observed on three MS media enriched with $1 \mathrm{mg} / \mathrm{L}$ BA and $1.5 \mathrm{mg} / \mathrm{L}$ NAA, $2 \mathrm{mg} / \mathrm{L} \mathrm{BA}$ and $1 \mathrm{mg} / \mathrm{L}$ NAA, and $2 \mathrm{mg} / \mathrm{L} \mathrm{BA}$ and $2 \mathrm{mg} / \mathrm{L}$ NAA. The best growth medium was the variant supplemented with $2 \mathrm{mg} / \mathrm{L}$ of each cytokinin and auxin.

All the methanolic extracts from the biomass were found to contain six PA: chlorogenic acid, 3,4-dihydroxyphenylacetic acid, $p$-hydroxybenzoic acid, neochlorogenic acid, protocatechuic acid, and rosmarinic acid (Fig. 2). The presence of the remaining fourteen compounds was not confirmed in any of the analysed extracts.

The total quantities of the investigated PA varied considerably, from 62.60 to $202.46 \mathrm{mg} / 100 \mathrm{~g} \mathrm{DW}$. The highest quantities were estimated on the medium with the addition of $1 \mathrm{mg} / \mathrm{L} \mathrm{BA}$ and $1 \mathrm{mg} / \mathrm{L} \mathrm{NAA} \mathrm{(Fig.} \mathrm{2).}$

The quantities of each PA varied within a very wide range, from 0.23 to approx. $92 \mathrm{mg} / 100 \mathrm{~g} \mathrm{DW}$. On the 


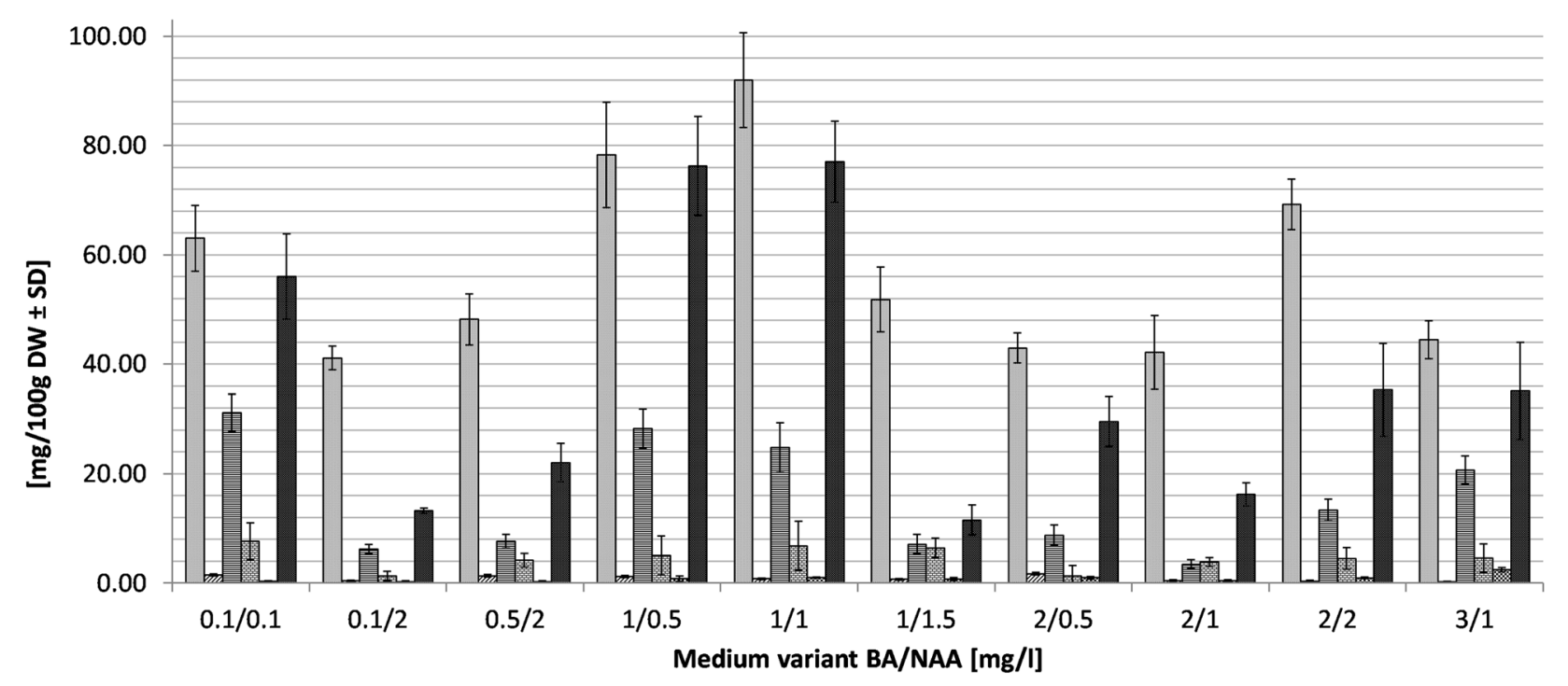

口Chlorogenic acid 国-Hydroxybenzoic acid 目 Neochlorogenic acid 3,4-Dihydroxyphenylacetic acid

圆 Protocatechuic acid

Rosmarinic acid

Fig. 2 Contents $(\mathrm{mg} / 100 \mathrm{~g} \mathrm{DW} \pm \mathrm{SD})$ of phenolic acids in extracts from shoot cultures of Aronia arbutifolia cultivated on MS medium variants with different concentrations of BA and NAA. The values are means of three experiments \pm SD

tested media, the quantities of the estimated compounds increased from 2.2 to 10.7 times. The main metabolites were DE-chlorogenic acid, rosmarinic acid, and neochlorogenic acid. In extracts from the shoots grown on all ten tested MS variants, the quantities of chlorogenic acid exceeded $40 \mathrm{mg} / 100 \mathrm{~g}$ DW. On two MS variants, supplemented with $1 \mathrm{mg} / \mathrm{L} \mathrm{BA}$ and $0.5 \mathrm{mg} / \mathrm{L}$ NAA, and $1 \mathrm{mg} / \mathrm{L}$ each of BA and NAA, these amounts were particularly high -78.29 and $91.94 \mathrm{mg} / 100 \mathrm{~g} \mathrm{DW}$, respectively. The quantities of rosmarinic acid varied more, from approx. 11.6 to approx. $77.0 \mathrm{mg} / 100 \mathrm{~g}$ DW. On three MS variants, the quantities of this depside did not exceed $16.5 \mathrm{mg} / 100 \mathrm{~g}$ DW. On three other MS variants, they were over $35 \mathrm{mg} / 100 \mathrm{~g}$ DW. The highest amounts (over $75 \mathrm{mg} / 100 \mathrm{~g} \mathrm{DW}$ ) were recorded in extracts from the shoots grown on two MS variants-one supplemented with $1.0 \mathrm{mg} / \mathrm{L} \mathrm{BA}$ and $0.5 \mathrm{mg} / \mathrm{L} \mathrm{NAA}$, and the other with $1 \mathrm{mg} / \mathrm{L}$ BA and $1 \mathrm{mg} / \mathrm{L}$ NAA. The maximum amounts of neochlorogenic acid were much lower, approx. $30 \mathrm{mg} / 100 \mathrm{~g}$ DW. The quantities of this DE ranged from 3.43 to $32.57 \mathrm{mg} / 100 \mathrm{~g}$ DW. The highest quantities were determined in extracts from the shoots grown on medium supplemented with $1.0 \mathrm{mg} / \mathrm{L}$ of BA and $1.0 \mathrm{mg} / \mathrm{L}$ of NAA.

The estimated amounts of three other compounds$p$-hydroxybenzoic, protocatechuic, and 3,4-dihydroxyphenylacetic acids - were of a different order of magnitude, not exceeded 1.75, 2.50, and $7.70 \mathrm{mg} / 100 \mathrm{~g} \mathrm{DW}$, respectively (Fig. 2).

\section{Callus cultures of Aronia arbutifolia}

The biomass of callus cultures of A. arbutifolia (Fig. 1) was morphologically similar on the investigated MS media (formed a dense, hard callus). Only on three MS variants enriched with $0.1 \mathrm{mg} / \mathrm{L} \mathrm{BA}$ and $2 \mathrm{mg} / \mathrm{L} \mathrm{NAA}, 1 \mathrm{mg} / \mathrm{L} \mathrm{BA}$ and $1.5 \mathrm{mg} / \mathrm{L} \mathrm{NAA}$, and especially with $0.1 \mathrm{mg} / \mathrm{L} \mathrm{BA}$ and $0.1 \mathrm{mg} / \mathrm{L}$ NAA was the formation of single shoots observed.

The increases in the dry biomass of callus determined during growth periods (4 weeks) on the ten investigated MS media were low, between 1.40 and 2.73 times. On four variants, these increases were more than 2.3 times. The best increase in biomass was shown on the medium supplemented with $2 \mathrm{mg} / \mathrm{L} \mathrm{BA}$ and $2 \mathrm{mg} / \mathrm{L}$ NAA.

In all the analysed extracts from callus, four out of the twenty analysed compounds were present: chlorogenic, 3,4-dihydroxyphenylacetic, neochlorogenic, and rosmarinic acids (Fig. 3).

The total quantities of these phenolic acids ranged from approx. 52 to approx. $87 \mathrm{mg} / 100 \mathrm{~g} \mathrm{DW}$. On nine variants, the total amounts of the metabolites exceeded $63 \mathrm{mg} / 100 \mathrm{~g}$ DW. On two variants (with $2 \mathrm{mg} / \mathrm{L}$ each of BA and NAA, and with $2 \mathrm{mg} / \mathrm{L} \mathrm{BA}$ and $1 \mathrm{mg} / \mathrm{L} \mathrm{NAA}$ ), those amounts were the highest ( 84.07 and $86.21 \mathrm{mg} / 100 \mathrm{~g} \mathrm{DW}$, respectively) (Fig. 3).

The quantities of each compounds varied widely, from 5.29 to $44.30 \mathrm{mg} / 100 \mathrm{~g}$ DW. On the MS media variants, they increased from 2.3 to 4.3 times. The dominant 


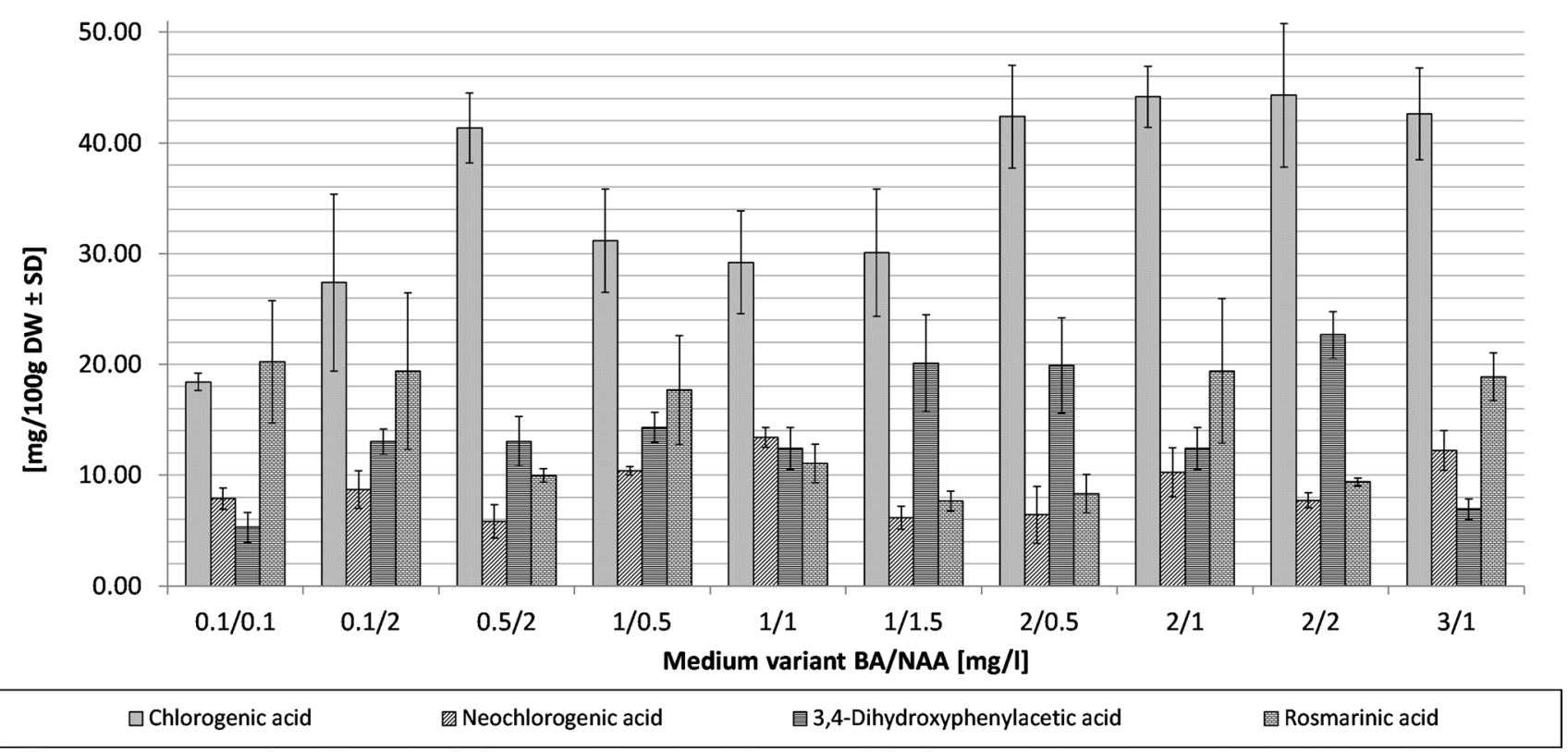

Fig. 3 Contents $(\mathrm{mg} / 100 \mathrm{~g}$ DW $\pm \mathrm{SD})$ of phenolic acids in extracts from callus cultures of Aronia arbutifolia cultivated on MS medium variants with different concentrations of BA and NAA. The values are means of three experiments \pm SD

compounds were two DE-chlorogenic and rosmarinic acids. The quantities of chlorogenic acid increased from 18.41 to $44.30 \mathrm{mg} / 100 \mathrm{~g}$ DW. On five variants, the amounts of this compound exceeded $40 \mathrm{mg} / 100 \mathrm{~g}$ DW. The highest, almost identical amounts, were confirmed in extracts from the callus grown on MS medium enriched with $2 \mathrm{mg} / \mathrm{L}$ $\mathrm{BA}$ and $2 \mathrm{mg} / \mathrm{L} \mathrm{NAA}$, and $2 \mathrm{mg} / \mathrm{L} \mathrm{BA}$ and $1 \mathrm{mg} / \mathrm{L} \mathrm{NAA}$ (44.30 and $44.17 \mathrm{mg} / 100 \mathrm{~g}$ DW, respectively). The highest quantity of rosmarinic acid was more than two times lower (20.24 mg/100 g DW). On five MS variants, the quantities of this metabolite were relatively high—over $17.5 \mathrm{mg} / 100 \mathrm{~g}$ DW. The maximum content was found on the MS variant supplemented with BA and NAA at $0.1 \mathrm{mg} / \mathrm{L}$ each. In the extracts of callus tissues, there were also found relatively high amounts of 3,4-dihydroxyphenylacetic acid (max. $24.21 \mathrm{mg} / 100 \mathrm{~g} \mathrm{DW}$ ). The quantities of this compound reached approx. $20 \mathrm{mg} / 100 \mathrm{~g}$ DW on three MS variants. The highest content was determined on the MS variant enriched with $2 \mathrm{mg} / \mathrm{L} \mathrm{BA}$ and $2 \mathrm{mg} / \mathrm{L}$ NAA. The quantities of neochlorogenic acid present in callus extracts were lower, ranging from 5.83 to $13.41 \mathrm{mg} / 100 \mathrm{~g} \mathrm{DW}$. The highest quantity was confirmed on the MS variant supplemented with $1 \mathrm{mg} / \mathrm{L}$ each of the two GRs (Fig. 3).

\section{Shoot cultures of Aronia $\times$ prunifolia}

Like the in vitro shoots of $A$. arbutifolia, the shoots of A. $\times$ prunifolia (Fig. 1) were also morphologically diversified on the investigated MS media. The shoots were more or less elongated, and formed more or less numerous green leafy shoots. On some MS media variants, containing $0.5 \mathrm{mg} / \mathrm{L} \mathrm{BA}$ and $2 \mathrm{mg} / \mathrm{L} \mathrm{NAA}, 2 \mathrm{mg} / \mathrm{L} \mathrm{BA}$, and $0.5 \mathrm{mg} / \mathrm{L}$, and especially $1 \mathrm{mg} / \mathrm{L} \mathrm{BA}$ and $1 \mathrm{mg} / \mathrm{L}$ NAA, the shoots formed some callus tissue at their base.

Aronia $\times$ prunifolia shoot cultures (Fig. 1) growing on the ten investigated MS media were characterized by varied increases in dry biomass, from 3.91- to 8.41-fold, during growth periods (4 weeks). The highest increases were found on the variant supplemented with $3 \mathrm{mg} / \mathrm{L} \mathrm{BA}$ and $1 \mathrm{mg} / \mathrm{L}$ NAA.

In extracts from the shoots cultured on all ten MS media, the presence of three DE-chlorogenic acid, neochlorogenic acid, and rosmarinic acid, and also protocatechuic acid (Fig. 4)-was confirmed. The amounts of the individual compounds differed from 1.37 to $257.39 \mathrm{mg} / 100 \mathrm{~g} \mathrm{DW}$. Their amounts increased from 1.60- to 4.81-fold, depending on the MS variant. Consequently, the total amount of these four metabolites ranged from approx. 220 to approx. $597 \mathrm{mg} / 100 \mathrm{~g}$ DW. The highest capacity for accumulating PA was shown by the shoots growing on MS variant supplemented with $0.1 \mathrm{mg} / \mathrm{L} \mathrm{BA}$ and $0.1 \mathrm{mg} / \mathrm{L}$ NAA (Fig. 4). The analysed extracts were notable for high amounts of three DE, especially rosmarinic and neochlorogenic acids, and also chlorogenic acid. The amounts of rosmarinic acid ranged from 93.86 to $206.62 \mathrm{mg} / 100 \mathrm{~g} \mathrm{DW}$, differed on the MS variant. The highest quantities (over $150 \mathrm{mg} / 100 \mathrm{~g} \mathrm{DW}$ ) were confirmed on three MS variants, those supplemented with BA and NAA at $0.1 \mathrm{mg} / \mathrm{L}$ each and $1.0 \mathrm{mg} / \mathrm{L}$ each (206.62 and $201.48 \mathrm{mg} / 100 \mathrm{~g} \mathrm{DW}$, respectively), and on the medium supplemented with $1 \mathrm{mg} / \mathrm{L} \mathrm{BA}$ and $0.5 \mathrm{mg} / \mathrm{L}$ 


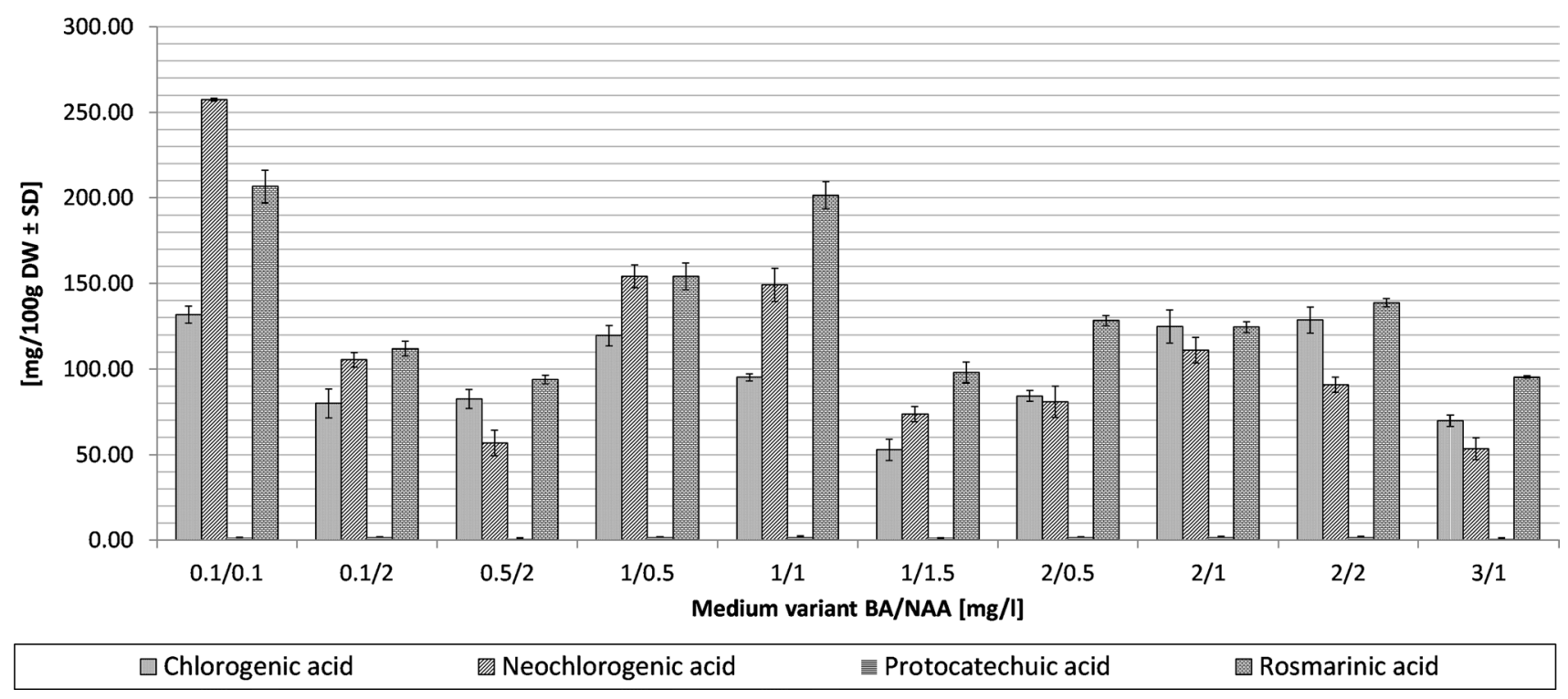

Fig. 4 Contents $(\mathrm{mg} / 100 \mathrm{~g}$ DW $\pm \mathrm{SD})$ of phenolic acids in extracts from shoot cultures of Aronia $\times$ prunifolia cultivated on MS medium variants with different concentrations of BA and NAA. The values are means of three experiments \pm SD

NAA (154.14 mg/100 g DW). The amounts of neochlorogenic acid also varied, approx. fivefold. Depending on the GRs levels added to the MS medium, the lowest and highest amounts of this compound were 53.51 and $257.39 \mathrm{mg} / 100 \mathrm{~g}$ DW, respectively. On five variants, the quantities of neochlorogenic acid exceeded $105 \mathrm{mg} / 100 \mathrm{~g}$ DW. On two of them, these amounts reached approx. $150 \mathrm{mg} / 100 \mathrm{~g}$ DW. These were the MS variants enriched with $1 \mathrm{mg} / \mathrm{L} \mathrm{BA}$ and $1 \mathrm{mg} / \mathrm{L} \mathrm{NAA}$, and $1 \mathrm{mg} / \mathrm{L}$ BA and $0.5 \mathrm{mg} / \mathrm{L}$ NAA (149.19 and $154.25 \mathrm{mg} / 100 \mathrm{~g} \mathrm{DW}$, respectively). The highest concentration of this metabolite was characteristic of the shoots growing on the variant with $0.1 \mathrm{mg} / \mathrm{L} \mathrm{BA}$ and $0.1 \mathrm{mg} / \mathrm{L}$ NAA. The quantities of chlorogenic acid varied too, approx. 2.5 -fold (from 52.89 to $131.82 \mathrm{mg} / 100 \mathrm{~g} \mathrm{DW}$ ). On four MS medium variants, the amounts of this metabolite exceeded $119 \mathrm{mg} / 100 \mathrm{~g}$ DW. The highest, almost identical, quantities were recorded in methanolic extracts from the shoots grown on the media supplemented with NAA and BA at $0.1 \mathrm{mg} / \mathrm{L}$ each and $2.0 \mathrm{mg} / \mathrm{L}$ each $(131.82$ and $128.62 \mathrm{mg} / 100 \mathrm{~g} \mathrm{DW}$, respectively). The fourth phenolic acid-protocatechuic acid-was present in the extracts in very low quantities, which did not exceed approx. $2 \mathrm{mg} / 100 \mathrm{~g} \mathrm{DW}$ (Fig. 4).

\section{Callus cultures of Aronia $\times$ prunifolia}

On all the tested MS medium variants, the biomass of callus cultures of A. $\times$ prunifolia (Fig. 1) looked similar. Moreover, the capacity for organogenesis was not observed on any of the tested medium variants. The callus tissue was very dense and hard.
The increases in the dry biomass of callus tissues of A. $\times$ prunifolia growing on the tested MS variants were low, from 1.8 to 2.4 times (during a 4 -week growth cycle). The highest, almost identical, increases (2.28-2.38 times) were found on three variants of MS medium enriched with BA and NAA in amounts of $1.0 \mathrm{mg} / \mathrm{L}$ each and $2.0 \mathrm{mg} / \mathrm{L}$ each, and on the medium with the addition of $0.5 \mathrm{mg} / \mathrm{L} \mathrm{BA}$ and $2 \mathrm{mg} / \mathrm{L}$ NAA.

The methanolic extracts from all the MS variants tested were proven to contain three DE-chlorogenic acid, rosmarinic acid, and neochlorogenic acid, and also protocatechuic acid (Fig. 5). Depending on the composition of the medium, they increased within a wide range, from 2.0to 20.0-fold. The total amounts of the above compounds increased approx. twofold, from 55.27 to $119.05 \mathrm{mg} / 100 \mathrm{~g}$ DW. On eight variants tested, the total amounts of these four compounds were greater than $75 \mathrm{mg} / 100 \mathrm{~g}$ DW. The highest capacity for accumulating DE was shown by the callus growing on two MS media supplemented with $1 \mathrm{mg} / \mathrm{L} \mathrm{BA}$ and $1 \mathrm{mg} / \mathrm{L}$ NAA (103.39 mg/100 g DW), and with $2 \mathrm{mg} / \mathrm{L}$ BA and $1 \mathrm{mg} / \mathrm{L}$ NAA (119.05 mg/100 g DW) (Fig. 5).

The callus was clearly notable for its ability to accumulate chlorogenic acid. The amounts of this quantitatively dominant metabolite ranged from 41.56 to $89.37 \mathrm{mg} / 100 \mathrm{~g}$ DW. On six MS variants, the quantities of chlorogenic acid exceeded $60 \mathrm{mg} / 100 \mathrm{~g}$ DW. Particularly, high quantities of chlorogenic acid were confirmed on the media supplemented with $1 \mathrm{mg} / \mathrm{L} \mathrm{BA}$ and $1 \mathrm{mg} / \mathrm{L}$ NAA $(78.30 \mathrm{mg} / 100 \mathrm{~g}$ DW), and $2 \mathrm{mg} / \mathrm{L} \mathrm{BA}$ and $1 \mathrm{mg} / \mathrm{L}$ NAA (max. content of $89.37 \mathrm{mg} / 100 \mathrm{~g} \mathrm{DW}$ ). The estimated quantities of the other two DE were much smaller, of a different order of 


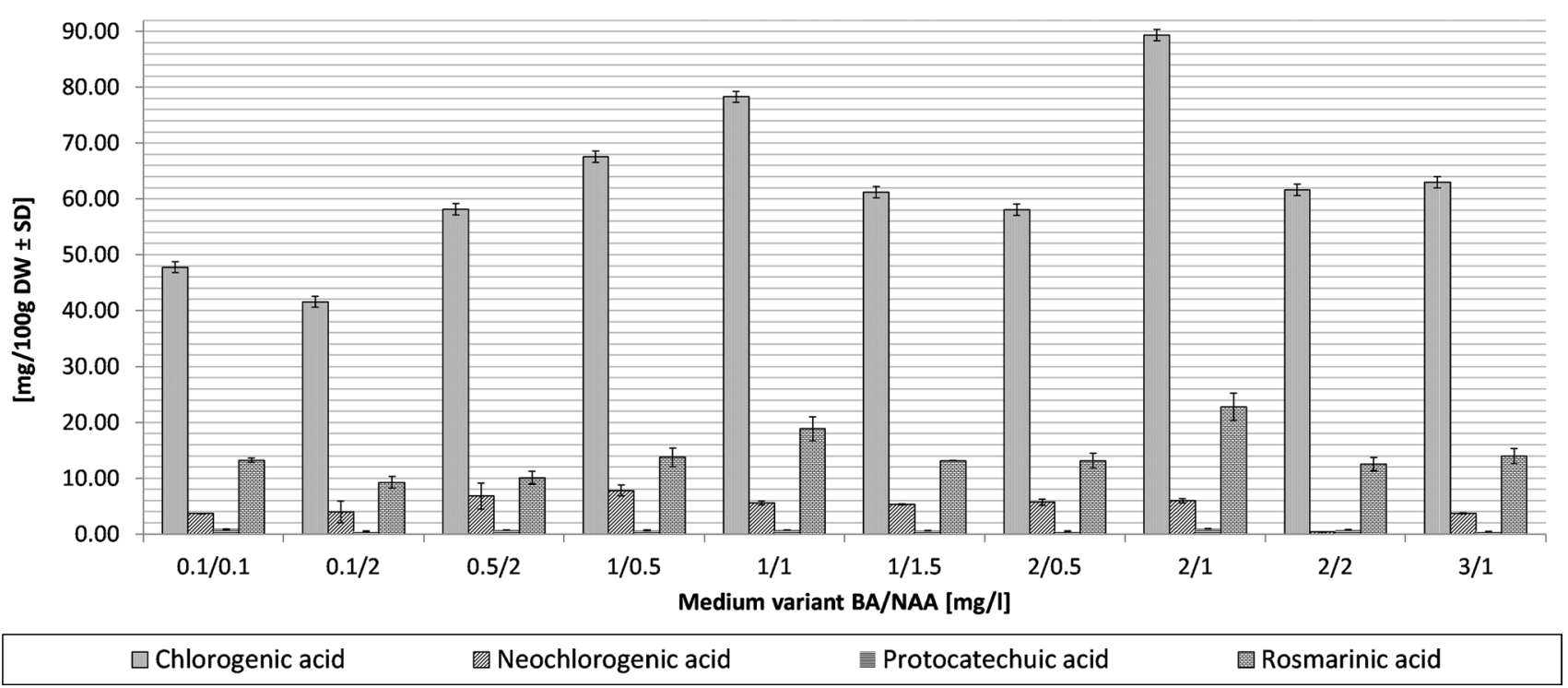

Fig. 5 Contents $(\mathrm{mg} / 100 \mathrm{~g}$ DW $\pm \mathrm{SD})$ of phenolic acids in extracts from callus cultures of Aronia $\times$ prunifolia cultivated on MS medium variants with different concentrations of BA and NAA. The values are means of three experiments \pm SD

magnitude. The amounts of neochlorogenic acid in callus extracts did not exceed $8.0 \mathrm{mg} / 100 \mathrm{~g} \mathrm{DW}$. The amounts of rosmarinic acid ranged from 9.21 to $22.78 \mathrm{mg} / 100 \mathrm{~g}$ DW. The quantities of protocatechuic acid did not exceed $1 \mathrm{mg} / 100 \mathrm{~g} \mathrm{DW}$ on any of the MS media tested (Fig. 5).

\section{Discussion}

The two types of in vitro cultures of Aronia arbutifolia and Aronia $\times$ prunifolia established in our department grew stably (Fig. 1). The incremental growth of calluses (max. 2.7- and 2.4-fold) was small. By contrast, the growth of microshoots of both plants was very good under optimized in vitro conditions. The highest increases in the biomass of microshoots of both plants (7.1-fold and 8.4-fold, respectively) were satisfactory. Increases of this order are higher than the average (four-fivefold) increases obtained in in vitro cultures of other plant species maintained in our department (Ekiert et al. 2009, 2014; Szopa and Ekiert 2011, 2012).

On the same initial medium, we obtained, in the in vitro culture initiation step, two different "lines"-shoot and callus lines of $A$. arbutifolia and $A$. $\times$ prunifolia (Fig. 1). On the tested experimental MS medium variants, we observed some differences in the morphology of shoots and calluses, but the two different experimental "lines"- -shoots and calluses-were always found growing on all the tested media variants. What was interesting, we did not observe the capacity for organogenesis in the callus lines grown on the media with different amounts of BA and NAA. The range of the tested GR amounts (0.1-3 mg/L) was comparable with the range tested by us in the experiment with shoot and callus in vitro cultures of A. melanocarpa (Szopa et al. 2013; Szopa and Ekiert 2014). The aim of the present study was to compare the biosynthetic potential of three aronias. In our earlier experiments with A. melanocarpa shoot and callus cultures maintained on LS and MS media variants, some differences in the morphology of tissues had also been observed, but they stayed as separately lines - shoot and callus lines (Szopa et al. 2013; Szopa and Ekiert 2014). In contrast, in our experiments with Hypericum perforatum cvs. Elixir, Helios, and Topas microshoot cultures, cultured on LS and MS media variants, we observed a more visible morphological diversity of the biomass (Kwiecień et al. 2015). On the media with higher concentrations of BA and NAA, we observed, after a very short time (3 weeks), the formation of large blocks of callus with single shoots on their surface. On the MS medium containing the lowest tested amounts of GRs ( $0.1 \mathrm{mg} / \mathrm{L} \mathrm{BA}$ and $0.1 \mathrm{mg} / \mathrm{L} \mathrm{NAA})$, only shoots were seen to grow. The results of other research teams had documented the same phenomenon that we noticed in the two Aronia cultures. On the same studied media variants containing the same concentrations of BA and NAA, the two different lines - shoot and callus lines of Echinocereus cinerascens-were forming and growing without a tendency to dedifferentiation or differentiation, respectively (Elias et al. 2014). To date, our experiences with in vitro cultures of medicinal plants have indicated that there are some genetic preferences of different plant species to form more or less differentiating lines in the beginning, and sometimes, it is very difficult to observe visible organogenesis in callus and dedifferentiation in shoot culture lines after changing the concentrations of GRs (Szopa and Ekiert 2012; Szopa et al. 2016; Ekiert et al. 2014; Kubica et al. 2017). Perhaps, in 
the in vitro cultures of studied aronias, the range of the GRs concentrations tested by us $(0.1-3 \mathrm{mg} / \mathrm{L})$ and the duration of experiment $(3 \times 4$ weeks $)$ were not enough to observe visible changes in the level of organogenesis.

Both in the shoot cultures and callus cultures of A. arbutifolia and A. $\times$ prunifolia, the amounts of the estimated compounds were clearly dependent on the quantities of the investigated GRs, BA and NAA, in the culture media, and increased, respectively, up to 10.7- and 4.3-fold, and up to 4.8- and 20.0-fold (Figs. 2, 3, 4, 5). Consequently, also the total PA content in A. arbutifolia cultures increased, up to 3.2- and about 1.7-fold. Similarly, in the shoot and callus cultures of $A . \times$ prunifolia, there was an increase in the total amount of compounds up to 2.7- and 2.1-fold, respectively, associated with the amounts of PGRs in MS media. This phenomenon nowadays is often studied as an important factor in green biotechnology. PGRs play a key role in the research focused on plant micropropagation (Gaj 2004; Sujatha and Kumari 2007; Biesaga-Kościelniak et al. 2010; Jana and Shekhawat 2011). The influence of the concentrations of GRs on the accumulation of different biogenetic groups of plant metabolites is an eminent fact (Ramawat and Mathur 2007). It has been proven, for example, in the accumulation of anthocyanins in callus cultures of Bridelia stipularis (Sreenivas et al. 2011), coumarins in callus cultures of Ammi majus (Ekiert and Gomółka 2000a) and Pastinaca sativa (Ekiert and Gomółka 2000b), secoiridoid and xanthone glycosides in shoot cultures of Gentiana dinarica (Branka et al. 2013), alkaloids in suspension cultures of Solanum eleagnifolium (Alvarez et al. 1993), triterpenes in callus cultures of Salvia tomentosa (Georgiev et al. 2011), verbascoside in callus cultures of Verbena officinalis (Kubica et al. 2017) and in the accumulation of podophyllotoxin in callus cultures of Hyptis suaveolens (Velóz et al. 2013) and dibenzocyclooctadiene lignans in shoot-differentiating callus cultures of Schisandra chinensis (Szopa and Ekiert 2011; Szopa et al. 2016, 2017b). The great influence of GRs on the production and accumulation of metabolites was also shown for PA in adventitious root cultures of Eryngium maritimum (Kikowska et al. 2014), in Ruta graveolens shoot cultures of (Ekiert et al. 2009), in R. g. ssp. divaricata (Ekiert et al. 2014), shoot-differentiating callus cultures and also in shoot cultures of Hypericum perforatum (cvs. Elixir, Helos, Topas) (Kwiecień et al. 2015). We had also proved this correlation based on our previous studies on shoot and callus cultures of black chokeberry (Szopa et al. 2013; Szopa and Ekiert 2014).

In $A$. arbutifolia shoot cultures, we found the highest total amounts of the estimated PA (over $189 \mathrm{mg} / 100 \mathrm{~g} \mathrm{DW}$ ) on two MS media supplemented with $1 \mathrm{mg} / \mathrm{L} \mathrm{BA}$ and $1 \mathrm{mg} / \mathrm{L}$ NAA, and $1 \mathrm{mg} / \mathrm{L} \mathrm{BA}$ and $0.5 \mathrm{mg} / \mathrm{L}$ NAA (Fig. 2). Media of these compositions can be proposed as good 'productive' media and at the same time as good 'growth' media, resulting in approx. 5.6- and 5.7-fold increments in biomass during growth periods (4 weeks). In A. arbutifolia callus cultures, we demonstrated the highest total amounts of PA (over $84 \mathrm{mg} / 100 \mathrm{~g} \mathrm{DW}$ ) on two other variants of MS medium, namely, on those supplemented with $2 \mathrm{mg} / \mathrm{L} \mathrm{BA}$ and $2 \mathrm{mg} / \mathrm{L}$ NAA, and $2 \mathrm{mg} / \mathrm{L} \mathrm{BA}$ and $1 \mathrm{mg} / \mathrm{L} \mathrm{NAA} \mathrm{(Fig.} \mathrm{3).} \mathrm{The} \mathrm{maxi-}$ mum production and maximum increases in biomass were found on the first-mentioned medium that medium can be a good 'productive' and parallel 'growth' medium for callus cultures.

In A. $\times$ prunifolia shoot cultures, the accumulation of the estimated compounds was promoted by three variants of MS medium (quantities of more than $429 \mathrm{mg} / 100 \mathrm{~g}$ DW). The variants were those containing BA and NAA at $0.1 \mathrm{mg} / \mathrm{L}$ each and $1.0 \mathrm{mg} / \mathrm{L}$ each, and the variant enriched with $1 \mathrm{mg} / \mathrm{L}$ BA and $0.5 \mathrm{mg} / \mathrm{L}$ NAA (Fig. 4). However, the increments in dry biomass on those variants were low. Only on the last of those MS variants were the increments in dry biomass of shoots quite high, approx. 5.8-fold, and a medium of that composition could potentially be considered as favourable to good increases in biomass and relatively high accumulation of the estimated compounds.

Considerable amounts of PA (over $100 \mathrm{mg} / 100 \mathrm{~g} \mathrm{DW}$ ) were confirmed in $A$. $\times$ prunifolia callus cultures cultivated on two investigated variants of MS medium. The variants were those supplemented with $1 \mathrm{mg} / \mathrm{L} \mathrm{BA}$ and $1 \mathrm{mg} / \mathrm{L} \mathrm{NAA \text {, }}$ and $2 \mathrm{mg} / \mathrm{L} \mathrm{BA}$ and $1 \mathrm{mg} / \mathrm{L} \mathrm{NAA} \mathrm{(Fig.} \mathrm{5).} \mathrm{Those} \mathrm{media}$ were also the only ones among the best 'growing' media. Therefore, they can be potentially proposed as 'productive' and parallel 'growth-promoting' media.

The shoot cultures, both A. arbutifolia and A. $\times$ prunifolia, had a higher capacity for accumulating free PA than the callus cultures did. The total amounts of the estimated compounds were 1.1-3.1 times (A. arbutifolia) and 2.7-9.1 times $($ A. $\times$ prunifolia $)$ higher in shoot extracts than in extracts from undifferentiated calluses growing on identical MS variants (Figs. 2, 3, 4, 5). Usually, a higher level of differentiation of in vitro cultivated biomass promotes the accumulation of secondary metabolites. This is a frequently observed relationship, e.g., considerable amounts of dibenzocyclooctadiene lignans can be obtained in shoots of S. chinensis (Szopa and Ekiert 2011), or PA in shoots of $R$. graveolens (Ekiert et al. 2009) and also in shoots of H. perforatum (cvs. Elixir, Helos, Topas) (Kwiecień et al. 2015). In addition, in shoots of black chokeberry cultured by us on both LS and MS media, the amounts of PA were, respectively, 1.3-2.9 and 1.6-4.1 times higher in comparison to the quantities in undifferentiated callus (Szopa et al. 2013; Szopa and Ekiert 2014).

The main metabolites that formed in the shoot and callus cultures of A. arbutifolia and A. $\times$ prunifolia were DEchlorogenic acid, rosmarinic acid, and neochlorogenic acid. The biosynthesis of these compounds, especially of 
chlorogenic acid and its isomer-neochlorogenic aciddoes not involve a long, complicated series of transformations. The components of these DE, quinic acid and caffeic acid, are formed via the shikimic acid pathway. The above-mentioned DE are, as our studies have indicated, also the main or the only ones of the main metabolites in the fruits of soil-grown A. arbutifolia and A. $\times$ prunifolia (Taheri et al. 2013; Szopa et al. 2017a). The in vitro cultured cells, despite artificial conditions, retain, therefore, the ability to biosynthesize these compounds. In in vitro cultures, they produce them in even larger quantities. The maximum amounts of DE obtained in shoot cultures of A. arbutifolia, particularly of chlorogenic acid (max. $91.94 \mathrm{mg} / 100 \mathrm{~g}$ DW) and rosmarinic acid (max. $77.03 \mathrm{mg} / 100 \mathrm{~g} \mathrm{DW}$ ), are paramount. Also noteworthy are the substantial amounts of neochlorogenic acid (max. $32.57 \mathrm{mg} / 100 \mathrm{~g} \mathrm{DW}$ ). In the case of chlorogenic acid and rosmarinic acid, these maximal amounts are 5.65 and 4.74 times, respectively, higher than in extracts from the fruit treated as reference material (16.27 and $16.24 \mathrm{mg} / 100 \mathrm{~g} \mathrm{DW})$. Only the quantities of neochlorogenic acid were higher in fruit extracts $(92.26 \mathrm{mg} / 100 \mathrm{~g}$ DW) (Table 1). The highest total PA amount in extracts from the biomass of the shoots was approx. 1.39 times higher than in the fruit (146.03 mg/100 g DW) (Table 2).

The highest quantities of DE confirmed in shoot cultures of $A . \times$ prunifolia were high (equal to)-chlorogenic acid (131.82 mg/100 g DW), neochlorogenic acid (257.39 mg/100 g DW), and rosmarinic acid (206.62 mg/100 g DW). In the case of rosmarinic acid and neochlorogenic acid, the maximum amounts are higher than in the fruit of soil-grown plants $(9.15$ and $219.34 \mathrm{mg} / 100 \mathrm{~g}$ DW, respectively). Only the quantities of chlorogenic acid are higher in fruit extracts $(280.23 \mathrm{mg} / 100 \mathrm{~g} \mathrm{DW})$. The highest total PA amount in extracts from the biomass from in vitro cultures is approx. 1.16 times higher than in extracts from the fruit $(513.14 \mathrm{mg} / 100 \mathrm{~g} \mathrm{DW})$. These results indicate a possibility of using $A$. arbutifolia and $A . \times$ prunifolia in vitro cultures as potential sources of PA, especially DE. Results from other research centres have also proved an interesting amount of DE in in vitro cultures of species representing various taxa, other than the families Lamiaceae and Boraginaceae, where the most prominent metabolite is rosmarinic acid (Ekiert et al. 2013). For example, significant amounts of DE-chlorogenic acid and rosmarinic acid-have been proven in cultures of Eryngium planum (Apiaceae) (Kikowska et al. 2012) and of chlorogenic acid in cultures of Hypericum perforatum (Hypericaceae) (Cui et al. 2010). In addition, our currently presented research results prove that in vitro cultures of the species of the family Rosaceae are also a rich source of DE.

The maximum amounts of the DE-chlorogenic acid, neochlorogenic acid, and rosmarinic acid, obtained in the cultures of the hybrid A. $\times$ prunifolia $(131.82,257.39$, and 206.62, respectively) - were higher than the maximum amounts obtained in the cultures of A. arbutifolia (91.94, 31.12 , and 77.03 , respectively). Interspecific hybrids are often characterized by a higher biosynthetic potential. This phenomenon is known and taken advantage of by the pharmaceutical industry. A good example can be Mentha $\times$ piperita, or Taxus $\times$ media, and the biosynthetic
Table 1 Contents (mg/100 g $\mathrm{DW} \pm \mathrm{SD}$ ) of phenolic acids in fruit extracts of soil-growth Aronia arbutifolia and their maximal contents in extracts from in vitro cultures
Table 2 Contents (mg/100 g $\mathrm{DW} \pm \mathrm{SD}$ ) of phenolic acids in fruit extracts of soil-growth Aronia $\times$ prunifolia and their maximal contents in extracts from in vitro cultures

\begin{tabular}{lcll}
\hline Phenolic acids & Shoot culture & Callus culture & Fruits \\
\hline Chlorogenic acid & $91.94 \pm 8.69$ & $44.30 \pm 6.48$ & $16.27 \pm 0.52$ \\
3,4-Dihydroxyphenylacetic acid & $7.64 \pm 0.35$ & $24.21 \pm 4.65$ & $20.80 \pm 0.13$ \\
$p$-Hydroxybenzoic acid & $1.73 \pm 0.23$ & nd & nd \\
Neochlorogenic acid & $32.57 \pm 2.23$ & $13.41 \pm 0.88$ & $92.26 \pm 3.26$ \\
Protocatechuic acid & $2.47 \pm 0.38$ & nd & $0.46 \pm 0.11$ \\
Rosmarinic acid & $77.03 \pm 7.40$ & $20.24 \pm 5.52$ & $16.24 \pm 0.34$ \\
Total content & $202.46 \pm 22.47$ & $86.21 \pm 13.39$ & $146.03 \pm 4.35$ \\
\hline
\end{tabular}

$n d$ not detected

\begin{tabular}{lllc}
\hline Phenolic acids & Shoot culture & Callus culture & Fruits \\
\hline Chlorogenic acid & $131.82 \pm 4.92$ & $89.37 \pm 2.04$ & $280.23 \pm 9.49$ \\
3,4-Dihydroxyphenylacetic acid & nd & nd & $219.34 \pm 8.65$ \\
Neochlorogenic acid & $257.39 \pm 0.74$ & $7.80 \pm 0.95$ & $219.34 \pm 10.19$ \\
Protocatechuic acid & $2.28 \pm 0.02$ & $0.94 \pm 0.07$ & $4.42 \pm 0.12$ \\
Rosmarinic acid & $206.62 \pm 9.55$ & $22.78 \pm 2.42$ & $9.15 \pm 0.98$ \\
Total content & $597.40 \pm 15.34$ & $119.05 \pm 4.88$ & $732.48 \pm 29.43$ \\
\hline
\end{tabular}

$n d$ not detected 
potential of the in vitro cultures of these hybrids (Hren et al. 2006; Wang et al. 2009; Sykłowska-Baranek et al. 2015).

The established in vitro cultures of $A$. arbutifolia and A. $\times$ prunifolia produce considerable, and thus interesting from a practical standpoint, amounts of DE-compounds of great importance in pharmacy and cosmetics. We nominate the established shoot cultures of $A$. $\times$ prunifolia as a valuable potential rich source of neochlorogenic acid and chlorogenic acid, and the shoot cultures of $A$. arbutifolia as an equally rich source of chlorogenic acid and rosmarinic acid.

Author contribution statement AS, PK, and AS conducted the research, compiled the data, and performed the chemical and the statistical analysis. AS and HE conceived the idea of the paper and prepared the manuscript. All the authors read and approved the manuscript in its final form.

Funding This work was supported by the Polish Ministry of Science and Higher Education (Grant Number K/ZDS/005614).

\section{Compliance with ethical standards}

Conflict of interest The authors declare that there are no conflicts of interests.

Open Access This article is distributed under the terms of the Creative Commons Attribution 4.0 International License (http://creativeco mmons.org/licenses/by/4.0/), which permits unrestricted use, distribution, and reproduction in any medium, provided you give appropriate credit to the original author(s) and the source, provide a link to the Creative Commons license, and indicate if changes were made.

\section{References}

Alvarez MA, Nigra HM, Giuuetti AM (1993) Solasodine production by Solanum eleagnifolium cav. in vitro cultures: influence of plant growth regulators, age and inoculum size, large-scale production. Nat Prod Lett 2:9-19. https://doi.org/10.1080/105756393080434 48

Biesaga-Kościelniak J, Kościelniak J, Janeczko A (2010) The impact of zearalenone and thidiazuron on indirect plant regeneration of oilseed rape and wheat. Acta Physiol Plant 32:1047-1053. https ://doi.org/10.1007/s11738-010-0495-9

Branka V, Dijana K-M, Teodora J et al (2013) Quantitative determination of secoiridoid and xanthone glycosides of Gentiana dinarica Beck cultured in vitro. Acta Physiol Plant 35:567-574. https://doi. org/10.1007/s11738-012-1098-4

Celka Z, Szkudlarz P (2010) Spontaneous occurrence and dispersion of Aronia $\times$ prunifolia [Marshall] Rehder [Rosaceae] in Poland on the example of the "Bagna" bog complex near Chlebowo [western Poland]. Acta Soc Bot Pol 79:37-42

Cui X-H, Chakrabarty D, Lee E-J, Paek K-Y (2010) Production of adventitious roots and secondary metabolites by Hypericum perforatum L. in a bioreactor. Biores Technol 101:4708-4716. https ://doi.org/10.1016/j.biortech.2010.01.115

Dewick PM (1997) Medicinal natural products. A biosynthetic approach. Wiley, Chichester
Döring AS, Petersen M (2014) Production of caffeic, chlorogenic and rosmarinic acids in plants and suspension cultures of Glechoma hederacea. Phytochem Lett 10:cxi-cxvii. https://doi. org/10.1016/j.phytol.2014.05.012

Ekiert H, Gomółka E (2000a) Coumarin compounds in Ammi majus L. callus cultures. Pharmazie 55:684-687

Ekiert H, Gomółka E (2000b) Furanocoumarins in Pastinaca sativa L. in vitro culture. Pharmazie 55:618-620

Ekiert H, Szewczyk A, Kuś A (2009) Free phenolic acids in Ruta graveolens L. in vitro culture. Pharmazie 64:100-102. https:// doi.org/10.1691/ph.2009.9592

Ekiert H, Kwiecień I, Szopa A (2013) Rosmarinic acid production in plant in vitro cultures. Pol J Cosmetol 16:49-58

Ekiert H, Piekoszewska A, Muszyńska B, Baczyńska S (2014) Accumulation of p-coumaric acid and other bioactive phenolic acids in in vitro culture of Ruta graveolens ssp. divaricata (Tenore) Gams. Med Intern Rev 26:24-31

Elias H, Taha RM, Hasbullah NA et al (2014) The effects of plant growth regulators on shoot formation, regeneration and coloured callus production in Echinocereus cinerascens in vitro. Plant Cell Tiss Organ Cult 120:729-739. https://doi.org/10.1007/ s11240-014-0642-x

Ellnain-Wojtaszek M, Zgórka G (1999) High-performance liquid chromatography and thin-layer chromatography of phenolic acids from Ginkgo biloba L. leaves collected within vegetative period. J Liq Chromatogr Rel Technol 22:1457-1471. https:// doi.org/10.1081/JLC-100101744

Gaj MD (2004) Factors influencing somatic embryogenesis induction and plant regeneration with particular reference to Arabidopsis thaliana (L.) Heynh. Plant Growth Regul 43:27-47

Georgiev V, Marchev A, Haas C et al (2011) Production of oleanolic and ursolic acids by callus cultures of Salvia tomentosa Mill. Biotechnol Biotechnol Equip 25:34-38. https://doi.org/10.5504/ BBEQ.2011.0129

Hren M, Baebler $\breve{S}$, Camloh M et al (2006) Yew (Taxus $\times$ media Rehd.) cell suspension cultures as a source of taxanes. Acta Physiol Plant 28:3-8. https://doi.org/10.1007/s1173 8-006-0061-7

Jana S, Shekhawat SG (2011) Plant growth regulators, adenine sulfate and carbohydrates regulate organogenesis and in vitro flowering of Anethum graveolens. Acta Physiol Plant 33:305-311. https:// doi.org/10.1007/s11738-010-0548-0

Kikowska M, Budzianowski J, Krawczyk A, Thiem B (2012) Accumulation of rosmarinic, chlorogenic and caffeic acids in in vitro cultures of Eryngium planum L. Acta Physiol Plant 34:2425-2433. https://doi.org/10.1007/s11738-012-1011-1

Kikowska M, Thiem B, Sliwinska E et al (2014) The effect of nutritional factors and plant growth regulators on micropropagation and production of phenolic acids and saponins from plantlets and adventitious root cultures of Eryngium maritimum L. J Plant Growth Regul 33:809-819. https://doi.org/10.1007/s0034 4-014-9428-y

Kokotkiewicz A, Jaremicz Z, Luczkiewicz M (2010) Aronia plants: a review of traditional use, biological activities, and perspectives for modern medicine. J Med Food 13:255-269. https://doi. org/10.1089/jmf.2009.0062

Kubica P, Szopa A, Ekiert H (2017) Production of verbascoside and phenolic acids in biomass of Verbena officinalis L. (vervain) cultured under different in vitro conditions. Nat Prod Res 31:16631668. https://doi.org/10.1080/14786419.2017.1286477

Kulling SE, Rawel HM (2008) Chokeberry (Aronia melanocarpa)a review on the characteristic components and potential health effects. Planta Med 74:1625-1634. https://doi. org/10.1055/s-0028-1088306

Kwiecień I, Szydłowska A, Kawka B et al (2015) Accumulation of biologically active phenolic acids in agitated shoot cultures of 
three Hypericum perforatum cultivars: "Elixir", "Helos" and “Topas". Plant Cell Tissue Organ Cult 123:273-281. https://doi. org/10.1007/s11240-015-0830-3

Linsmaier EM, Skoog F (1965) Organic growth factor requirements of tobacco tissue cultures. Physiol Plant 18:100-127. https://doi. org/10.1111/j.1399-3054.1965.tb06874.x

Meng S, Cao J, Feng Q et al (2013) Roles of chlorogenic acid on regulating glucose and lipids metabolism: a review. Evid Based Complement Altern Med 2013:801457. https://doi. org/10.1155/2013/801457

Murashige T, Skoog F (1962) A revised medium for rapid growth and bioassays with tobacco tissue cultures. Physiol Plant 15:473-479

Nakatani N, Kayano S, Kikuzaki H et al (2000) Identification, quantitative determination, and antioxidative activities of chlorogenic acid isomers in prune (Prunus domestica L.). J Agric Food Chem 48:5512-5516. https://doi.org/10.1021/jf000422s

Petersen M, Simmonds MSJ (2003) Rosmarinic acid. Phytochemistry 62:121-125

Ramawat K, Mathur M (2007) Factors affecting the production of secondary metabolites. In: Ramawat K, Merillon J (eds) Biotechnology: secondary metabolites, plants and microbes. Science Publ Inc, Jersey, pp 59-102

Sato Y, Itagaki S, Kurokawa T et al (2011) In vitro and in vivo antioxidant properties of chlorogenic acid and caffeic acid. Int J Pharm 403:136-138. https://doi.org/10.1016/j.ijpharm.2010.09.035

Sreenivas VK, Jisha VN, Martin KP, Madhusoodanan PV (2011) Bridelia stipularis: a new source for anthocyanin production in vitro. Acta Physiol Plant 33:2051-2056. https://doi.org/10.1007/s1173 8-011-0735-7

Sujatha G, Kumari BDR (2007) Effect of phytohormones on micropropagation of Artemisia vulgaris L. Acta Physiol Plant 29:189-195. https://doi.org/10.1007/s11738-006-0023-0

Sykłowska-Baranek K, Grech-Baran M, Naliwajski MR et al (2015) Paclitaxel production and PAL activity in hairy root cultures of Taxus $\times$ media var. Hicksii carrying a taxadiene synthase transgene elicited with nitric oxide and methyl jasmonate. Acta Physiol Plant 37:218. https://doi.org/10.1007/s11738-015-1949-x

Szopa A, Ekiert H (2011) Lignans in Schisandra chinensis in vitro cultures. Pharmazie 66:633-634

Szopa A, Ekiert H (2012) In vitro cultures of Schisandra chinensis (Turcz.) Baill. (Chinese magnolia vine)—a potential biotechnological rich source of therapeutically important phenolic acids. Appl Biochem Biotechnol 166:1941-1948. https://doi. org/10.1007/s12010-012-9622-y
Szopa A, Ekiert H (2014) Production of biologically active phenolic acids in Aronia melanocarpa (Michx.) Elliott in vitro cultures cultivated on different variants of the Murashige and Skoog medium. Plant Growth Regul 72:51-58. https://doi.org/10.1007/ s10725-013-9835-2

Szopa A, Ekiert H, Muszyńska B (2013) Accumulation of hydroxybenzoic acids and other biologically active phenolic acids in shoot and callus cultures of Aronia melanocarpa (Michx.) Elliott (black chokeberry). Plant Cell Tiss Organ Cult 113:323-329. https://doi. org/10.1007/s11240-012-0272-0

Szopa A, Kokotkiewicz A, Marzec-Wróblewska U et al (2016) Accumulation of dibenzocyclooctadiene lignans in agar cultures and in stationary and agitated liquid cultures of Schisandra chinensis (Turcz.) Baill. Appl Microbiol Biotechnol 100:3965-3977. https ://doi.org/10.1007/s00253-015-7230-9

Szopa A, Kokotkiewicz A, Kubica P et al (2017a) Comparative analysis of different groups of phenolic compounds in fruit and leaf extracts of Aronia sp.: A. melanocarpa, A. arbutifolia, and A. $\times$ prunifolia and their antioxidant activities. Eur Food Res 243:1645-1657. https://doi.org/10.1007/s00217-017-2872-8

Szopa A, Kokotkiewicz A, Łuczkiewicz M, Ekiert H (2017b) Schisandra lignans production regulated by different bioreactor type. J Biotechnol 247:11-17. https://doi.org/10.1016/j.jbiot ec.2017.02.007

Taheri R, Connolly BA, Brand MH, Bolling BW (2013) Underutilized chokeberry (Aronia melanocarpa, Aronia arbutifolia, Aronia prunifolia) accessions are rich sources of anthocyanins, flavonoids, hydroxycinnamic acids, and proanthocyanidins. J Agric Food Chem 61:8581-8588. https://doi.org/10.1021/jf402449q

Thurow T (2012) Effect of chlorogenic acid and neochlorogenic acid on human colon cancer cells. Food Science Undergraduate Honors Theses. http://scholarworks.uark.edu/fdscuht/2

Valcheva-Kuzmanova S, Belcheva A (2006) Current knowledge of Aronia melanocarpa as a medicinal plant. Fol Med 48:11-17

Velóz RA, Cardoso-Taketa A, Villarreal ML (2013) Production of podophyllotoxin from roots and plantlets of Hyptis suaveolens cultivated in vitro. Pharmacogn Res 5:93-102. https://doi. org/10.4103/0974-8490.110538

Wang X, Gao Z, Wang Y et al (2009) Highly efficient in vitro adventitious shoot regeneration of peppermint (Mentha $\times$ piperita L.) using internodal explants. In Vitro Cell Dev Biol Plant 45:435. https://doi.org/10.1007/s11627-008-9170-x 